\title{
Staple Line Polyposis and Cytomegalovirus Infection after Stapled Haemorrhoidectomy
}

\author{
Abdul-Wahed N. Meshikhes Hussain Issa \\ Department of Surgery, King Fahad Specialist Hospital, Dammam, Saudi Arabia
}

\section{Key Words}

Haemorrhoids · Rectal cancer · Stapled haemorrhoidectomy · Complications

\begin{abstract}
Early bleeding after stapled haemorrhoidectomy (SH) is not uncommon. Late and persistent bleeding occurring weeks or months after $\mathrm{SH}$, however, is rare; it has only been described in more than $10 \%$ of cases. It is attributed to the development of inflammatory polyps at the staple line. Occurrence of rectal bleeding in the presence of palpable polypoid lesions at the stapled anastomotic line can cause diagnostic confusions, and it is not uncommon that such lesions are initially confused with rectal carcinoma. We report a case of a 38-year-old male who presented with persistent rectal bleeding some 6 months after SH performed in another hospital. Rectal and colonoscopic examinations revealed polypoid lesions at the anastomotic line. The biopsy failed to confirm malignancy, but identified cytomegalovirus (CMV) infection. The development of multiple inflammatory polypoid lesions in conjunction with CMV infection at the stapled anastomotic line has caused a diagnostic confusion, but - after exclusion of cancer - this complication was efficiently treated by CMV infection eradication combined with surgical excision of the remaining polyps due to persistence of bleeding. This case is reported to highlight late bleeding due to inflammatory polyps after $\mathrm{SH}$ and to increase the awareness of surgeons and gastroenterologists of this benign but somewhat common complication.
\end{abstract}

\section{Introduction}

Haemorrhoids or piles are a common surgical ailment affecting many individuals in the world. Treatment of haemorrhoids is diverse, but the best treatment is prevention which can be achieved by avoiding constipation, intake of a high-fibre diet and administration of bulk laxatives, if necessary. Local symptoms such as anal irritation and pain can be alleviated by soothing creams and suppositories, but they hardly provide long-term benefit. Although nonsurgical treatments of piles such as rubber band ligation, 
sclerotherapy, photocoagulation and cryotherapy are well accepted and very popular among patients, they are not suitable for all grades of haemorrhoids. Hence, for piles that are not suitable for nonsurgical treatment and for those which fail to respond to medical treatment, surgical intervention become a necessity. These surgical procedures vary from gentle anal sphincter dilatation to standard Milligan-Morgan haemorrhoidectomy. The latter is often associated with morbidity, severe pain and discomfort, which results in a bad reputation and makes it unpopular among patients. A reasonably new promising operation that is suitable especially for piles that are accompanied by mucosal prolapse is stapled haemorrhoidectomy (SH). This procedure was introduced by Longo [1] and it has been gaining popularity due to its numerous advantages and is now accepted as one of the procedures of choice for the treatment of prolapsing haemorrhoids [2, 3]. It is associated with much less postoperative pain, early discharge and return to work [4]. Although it has been hailed as safe and effective, short- and long-term complications have been reported, some of which are life-threatening [5-7]. Such complications include staple line bleeding, stenosis, pelvic sepsis, rectovaginal fistula, rectal lumen obliteration, acute rectal obstruction and perforation [7-9].

Early staple line bleeding after $\mathrm{SH}$ is not uncommon. However, late and persistent bleeding that occurs weeks or even months after SH is rare; it has only been described in more than $10 \%$ of cases [10]. It is attributed to the development of inflammatory polyps at the staple line. Occurrence of rectal bleeding in the presence of such palpable polypoid lesions can cause diagnostic confusions, and it is not uncommon that such inflammatory polyps may be initially mistaken for rectal carcinoma. Coexisting cytomegalovirus (CMV) infection of the rectum may aggravate the development of these inflammatory polyps and may contribute to the persistence of rectal bleeding.

We report such a late staple line complication which occurred in conjunction with CMV infection some 6 months after a uneventful SH.

\section{Case Report}

A 38-year old male patient presented with bleeding per rectum and a 1-year history of constipation. He underwent colonoscopy, which was normal, and SH was performed 6 months earlier in another hospital with early improvement in his haemorrhoidal symptoms. However, 4 weeks later, he started to complain of rectal bleeding on defaecation again, which became progressively worse. He had no past history of inflammatory bowel disease (IBD), diabetes or homosexual tendencies, and his family history of IBD and colorectal cancer was negative. Abdominal examination was unremarkable, but rectal examination revealed multiple polypoid lesions at the level of the anastomotic line. Routine blood tests, C-reactive protein levels and tumour markers were within normal limits and the HIV status was negative. Colonoscopy revealed multiple inflammatory polyps at the staple line (fig. 1). Due to high clinical suspicion of malignancy, computerized tomography (CT) scan was ordered, with rectal contrast showing multiple polypoid lesions in the lower rectum with diffuse circumferential wall thickening extending from the rectosigmoid junction down to the anorectal ring (fig. 2). The histology of the colonoscopic biopsy showed an inflammatory response with evidence of CMV infection. He was started on ganciclovir therapy, but his bleeding symptoms persisted, and a second sigmoidoscopy 6 weeks later revealed a marked improvement in the endoscopic features of the polyps (fig. 3). His bleeding ceased completely after simple surgical excision of the remaining polyps and 2 staples at the anastomotic line. The final histology revealed inflammatory polyps with no evidence of malignancy or CMV infection. He remained totally asymptomatic at the 12-month follow-up.

\section{Discussion}

Although SH has been considered one of the procedures of choice for the treatment of prolapsing haemorrhoids $[2,3]$ and has been hailed as safe and effective, it is associated 
with some short- and long-term complications which are attributed to a breach in the mucosal lining at the anastomotic line. The most serious complications are rectovaginal fistula, rectal perforation and deep pelvic sepsis which may prove fatal in some cases [4, 6-9]. This case highlights yet another staple line complication, although it was not lifethreatening, but caused diagnostic dilemma and confusion. This patient developed multiple polypoid lesions which were felt clinically to be malignant, but proved to be inflammatory polyps which may well be associated with CMV proctitis based on the histological examination of the colonoscopic biopsies and the CT scan examinations. Therefore, the patient was started on ganciclovir therapy which resulted in a marked improvement in the endoscopic appearance but had no significant effect on his symptoms. Surgical excision of the remaining polyps led to the complete disappearance of the patient's symptoms. The marked improvement in the endoscopic features of the polyps after treatment with ganciclovir may indicate that CMV infection could have played an important role in increasing the intensity of the inflammatory reaction at the staple line, with the subsequent development of the polyps. This CMV infection may also explain the associated thickening in the rectal wall that was seen on the CT scan. However, it is difficult to establish retrospectively whether the patient has harbored CMV infection or not as the $\mathrm{SH}$ procedure was performed in another hospital.

CMV infection of the colorectum is usually observed in immunocompromised individuals such as diabetics and HIV patients in whom it can be life-threatening. It has also been reported in immunocompetent individuals, but is usually mild and subclinical as in this case [11]. However, severe CMV proctitis with massive fatal rectal bleeding in immunocompetent patients has also been described [11]. Although a strong association between CMV infection and severe ulcerative colitis exists (CMV positivity 57\%) $[12,13]$, the association with colorectal cancer is very weak or even nonexistent (CMV positivity $14 \%$ only) $[14,15]$. Nevertheless, it may masquerade radiologically and endoscopically as cancer, especially in immunocompromised patients $[15,16]$.

In the study by Fondran et al., late and persistent bleeding due to inflammatory polyps at the staple line weeks or months after SH has been described in $11 \%(9 / 82)$ of patients [10]. Like in this case, the bleeding was mild and resolved in all cases after surgical excision of the polyps [14]. Fondran et al. concluded that bleeding from inflammatory polyps occurs in a significant number of patients undergoing $\mathrm{SH}$ [10]. It was also recommended that such bleeding several weeks or months after the procedure should prompt a search for inflammatory polyps at the staple line and that simple surgical excision is adequate to prevent rebleeding [10]. Quah et al. described 2 patients with persistent fresh rectal bleeding due to inflammatory polyps occurring more than 12 months following SH [17]. Drummond and Wright also observed this bleeding occurrence in a patient presenting with intermittent bleeding per rectum 4 years after $\mathrm{SH}$ [18]. Examination under anaesthesia revealed palpable staples protruding from the mucosa which appeared to show signs of recent bleeding [18]. There was no other pathology noted and the staples were thus removed [18]. It is speculated that passage of stools over residual staples can result in recurrent local trauma and subsequent bleeding [18]. This may be the cause of the persistent bleeding even after CMV eradication in this case, as loose staples were found in the anastomotic line (fig. 3). Staple line reinforcement by sutures to stop the immediate bleeding that occurs after firing the staplers has been implicated as a precursor to polyp formation. However, in this case, it is not clear whether the formation of the polyps was related to the reinforcement by sutures as the surgery was carried out somewhere else. Generally speaking, it is believed that intense inflammatory reaction may be triggered by staples as this complication is also observed in non-suturereinforced anastomoses [10]. Whether these polyps develop as a result of an inflammatory 


\begin{tabular}{r|l|l|l}
$\begin{array}{r}\text { Case Reports } / \mathrm{h} \\
\text { Gastruenterelogy }\end{array}$ & $\begin{array}{l}\text { Case Rep Gastroenterol 2010;4:204-209 } \\
\text { Dol: 10.1159/000316634 }\end{array}$ & Published online: June 19, 2010 & $\begin{array}{l}\text { @ 2010 S. Karger AG, Basel } \\
\text { ISSN 1662-0631 } \\
\text { www.karger.com/crg }\end{array}$ \\
\hline
\end{tabular}

reaction to exposed staples, staple line reinforcement by sutures, or due to CMV proctitis as in this case, it is not uncommon for inflammatory polyps to be initially confused with cancer.

This case highlights the possible development of inflammatory polyps at the anastomotic line which may be aggravated by superimposed CMV infection several months after SH. This complication may initially masquerade as rectal cancer. Hence, it cannot be overemphasized that awareness of this benign complication and exclusion of cancer is of prime importance to avoid unnecessary surgery for an inflammatory condition.

\section{Acknowledgement}

The authors would like to thank Dr. Abdul Jaleel Poovathumkadavil, MD consultant radiologist, Department of Body Imaging, King Fahad Specialist Hospital, Dammam, Saudi Arabia, for provision of figure 2.

Fig. 1. Colonoscopic view of the anastomotic line polyposis at presentation. Note the close resemblance to polypoid rectal cancer. The histopathology of the biopsy revealed an inflammatory response with CMV infection.

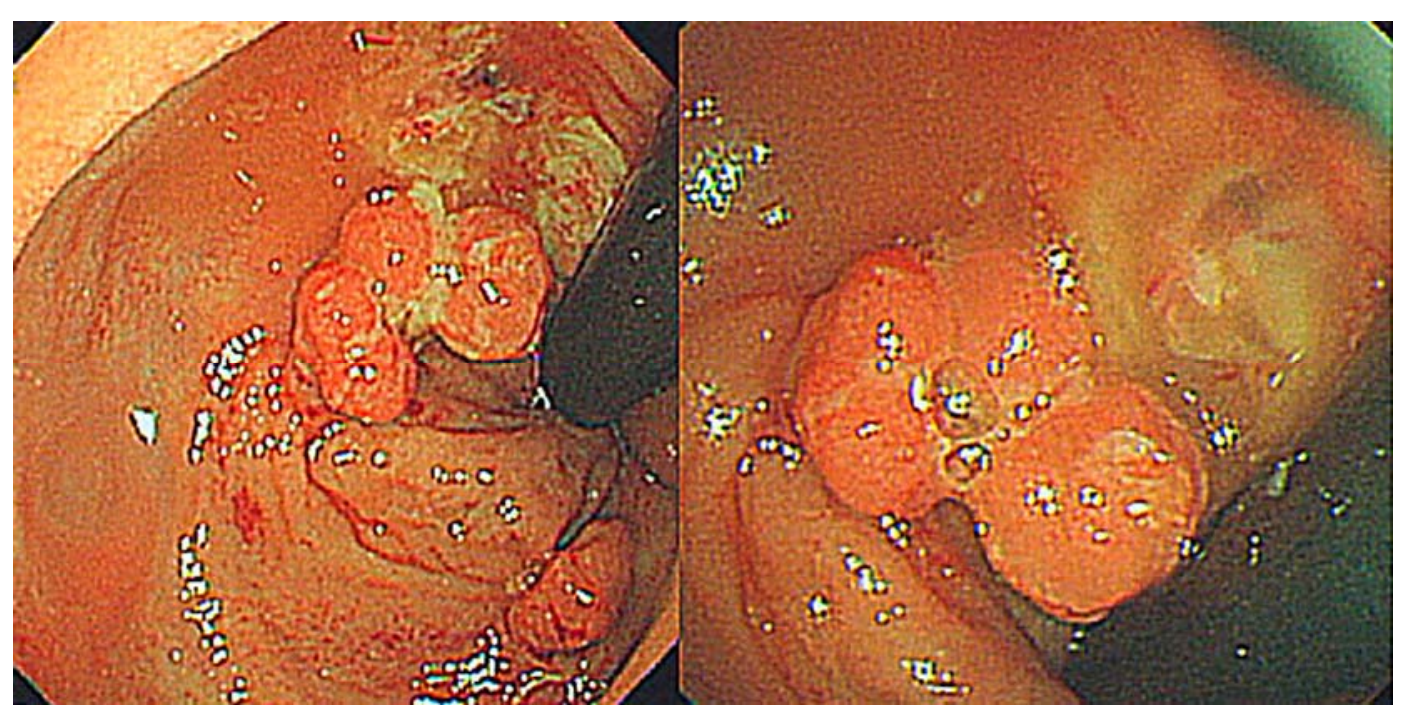




\begin{tabular}{r|l|l|l} 
Case Reports $/ \mathrm{h}$ & $\begin{array}{l}\text { Case Rep Gastroenterol 2010;4:204-209 } \\
\text { D0l: 10.1159/000316634 }\end{array}$ & Published online: June 19, 2010 & $\begin{array}{l}\text { O 2010 S. Karger AG, Basel } \\
\text { ISSN 1662-0631 } \\
\text { www.karger.com/crg }\end{array}$ \\
\hline
\end{tabular}

Fig. 2. Axial CT scan (a) following rectal and intravenous contrast with coronal reconstructed images (b), showing multiple polypoid lesions in the lower third of the rectal lumen (arrows). Those lesions correspond well to the polypoid lesions which are seen during colonoscopy. The rectal wall is minimally thickened as a result of the inflammation.
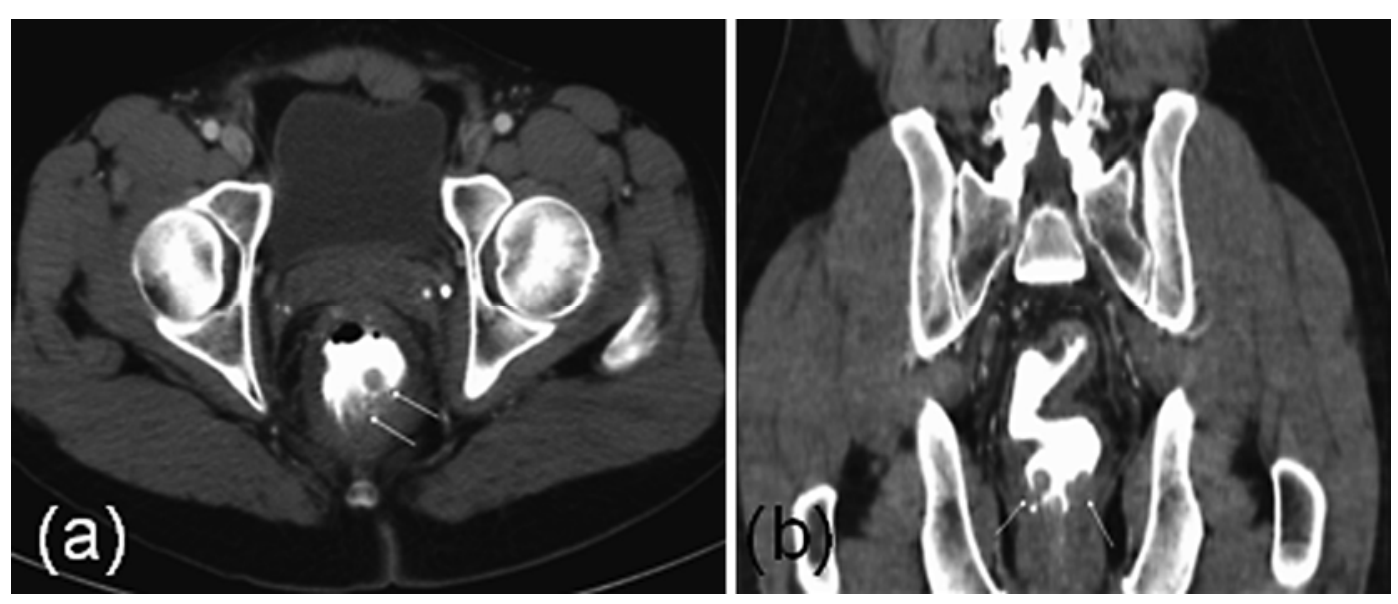

Fig. 3. Colonoscopic view of the anastomotic line 6 weeks after treatment with anti-CMV therapy (ganciclovir), showing near complete resolution of the polyps. Note the remaining staples at the anastomotic line which may be the cause of continuous bleeding due to trauma during defaecation rather than the persistence of the polyps.

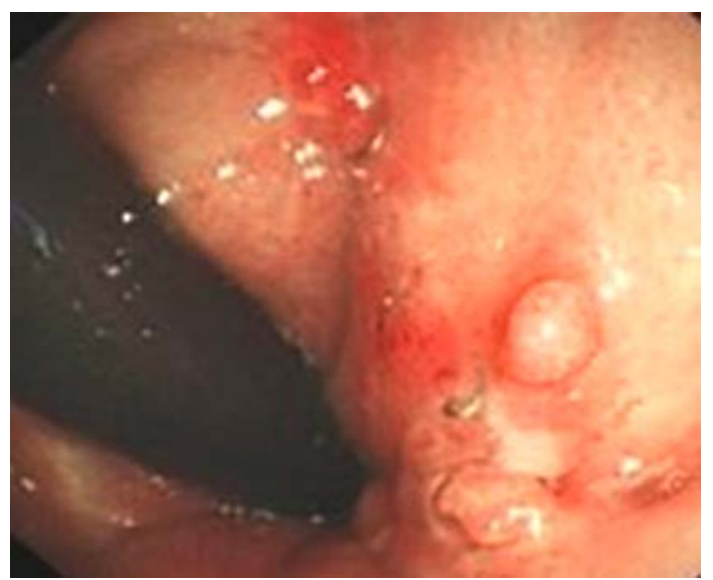




\section{References}

1 Longo A: Treatment of haemorrhoids disease by reduction of mucosa and haemorrhoidal prolapse with circular suturing device: a new procedure. Proceeding of the 6th World Congress of Endoscopic Surgery; 1998 June 3-6; Rome, Italy. Bologna, Monduzzi Editore, 1998, pp 777-784.

-2 Kraemer M, Parulava T, Roblick M, Duschka L, Müller-Lobeck H: Prospective, randomized study: proximate $\mathrm{PPH}$ stapler vs. LigaSure for hemorrhoidal surgery. Dis Colon Rectum 2005;48:1517-1522.

-3 Gravié JF, Lehur PA, Huten N, Papillon M, Fantoli M, Descottes B, Pessaux P, Arnaud JP: Stapled hemorrhoidopexy versus Milligan-Morgan hemorrhoidectomy: a prospective, randomized, multicenter trial with 2-year postoperative follow up. Ann Surg 2005;242:29-35.

-4 Beattie GC, McAdam TK, McIntosh SA, Loudon MA: Day case stapled haemorrhoidopexy for prolapsing haemorrhoids. Colorectal Dis 2006;8:56-61.

5 Wong LY, Jiang JK, Chang SC, Lin JK: Rectal perforation: a life-threatening complication of stapled hemorrhoidectomy: report of a case. Dis Colon Rectum 2003;46:116-117.

6 Mongardini M, Custureri F, Schillaci F, Cola A, Maturo A, Fanello G, Corelli S, Pappalardo G: Rectal stenosis after stapler hemorrhoidopexy. G Chir 2005;26:275-277.

-7 Jongen J, Bock JU, Peleikis HG, Eberstein A, Pfister K: Complications and reoperations in stapled anopexy: learning by doing. Int J Colorectal Dis 2006;21:166-171.

8 Brown S, Baraza W, Shorthouse A: Total rectal lumen obliteration after stapled haemorrhoidopexy: a cautionary tale. Tech Coloproctol 2007;11:357-358.

-9 Cipriani S, Pescatori M: Acute rectal obstruction after PPH stapled haemorrhoidectomy. Colorectal Dis 2002;4:367-370.

10 Fondran JC, Porter JA, Slezak FA: Inflammatory polyps: a cause of late bleeding in stapled hemorrhoidectomy. Dis Colon Rectum 2006;49:1910-1913.

11 Alam I, Shanoon D, Alhamdani A, Boyd A, Griffiths AP, Baxter JN: Severe proctitis, perforation, and fatal rectal bleeding secondary to cytomegalovirus in an immunocompetent patient: report of a case. Surg Today 2007;37:66-69.

-12 Mariguela VC, Chacha SGF, Cunha AD, Troncon LE, Zucoloto S, Figueiredo LTM: Cytomegalovirus in colorectal cancer and idiopathic ulcerative colitis. Rev Inst Med Trop Sao Paulo 2008;50:83-87.

13 Kojima T, Watanabe T, Hata K, Shinozaki M, Yokoyama T, Nagawa H: Cytomegalovirus infection in ulcerative colitis. Scand J Gastroenterol 2006;41:706-711.

-14 Akintola-Ogunremi O, Luo Q, He TC, Wang HL: Is cytomegalovirus associated with human colorectal tumorigenesis? Am J Clin Pathol 2005;123:244-249.

15 Chow PK, Ho JM, Ling AE, Goh HS: CMV colitis masquerading as colon cancer an unusual presentation of acquired immunodeficiency syndrome. Singapore Med J 1997;38:32-34.

16 Falagas ME, Griffiths J, Prekezes J, Worthington M: Cytomegalovirus colitis mimicking colon carcinoma in an HIV-negative patient with chronic renal failure. Am J Gastroenterol 1996;91:168-169.

-17 Quah HM, Hadi HI, Hay DJ, Maw A: Residual staples as a possible cause of recurrent rectal bleeding after stapled haemorrhoidectomy. Colorectal Dis 2003;5:196.

18 Drummond R, Wright DM: Continued rectal bleeding following stapled haemorrhoidectomy. Colorectal Dis 2007;9:669-670. 